\title{
FILOSOFIA, CULTURA E POLÍTICA JURÍDICA
}

Josemar Soares ${ }^{1}$

\section{Resumo:}

A filosofia é exercício racional capaz de colocar sob exame crítico qualquer objeto, incluindo a dimensão cultural. Há a ontologia da cultura, que depois continua em uma ética da cultura, porque a cultura também possibilita a normatividade (direito) do comportamento humano. $\mathrm{O}$ presente artigo tem por objetivo apresentar a Filosofia como instrumento capaz de auxiliar a Política Jurídica no exame crítico da cultura jurídica vigente. Por problema de pesquisa, portanto, tem-se: pode a filosofia ser instrumento de auxílio da Política Jurídica no exame crítico do direito enquanto manifestação cultural? $\mathrm{O}$ artigo utiliza o método dedutivo, por meio de pesquisa bibliográfica.

Palavras-chave:

Filosofia; Cultura; Política Jurídica; Produção do Direito; Ontologia.

\begin{abstract}
:
Philosophy is a rational exercise capable of placing any object under critical examination, including the cultural dimension. There is the ontology of culture, which then continues in an ethics of culture, because culture also enables the normativity (right) of human behavior. The purpose is to present Philosophy as an instrument capable of assisting Legal Policy in the critical examination of the current legal culture. For research problem, therefore, there is: can philosophy be an instrument to assist Legal Policy in the critical examination of law as a cultural manifestation? The article uses the deductive method, through bibliographic research.
\end{abstract}

Keywords:

Philosophy; Culture; Legal Policy; Production of Law; Ontology.

\section{INTRODUÇÃO}

A Política Jurídica é o estudo que procura identificar como o direito deveria ser, como o direito deveria ser estabelecido historicamente para melhor organizar as condições de vida das pessoas em dado tempo e espaço. Já desde Kelsen se entende a ciência jurídica como estudo o direito que é, direito posto, sistematizado, e como aplicá-lo, e a política jurídica a busca a responder como o direito deveria ser. Para isto, evidentemente, deve recorrer a estudos e conteúdos que transcendem o mundo jurídico, trazendo para o debate elementos filosóficos, sociológicos, políticos, etc.

A Política Jurídica lida com o mundo da cultura, porque a partir dela pode extrair

\footnotetext{
${ }^{1}$ Doutor em Filosofia pela Universidade Federal do Rio Grande do Sul - UFRGS; Mestre em Educação pela Universidade Federal de Santa Maria - UFSM e em Ciência Jurídica pela Universidade do Vale do Itajaí UNIVALI. Professor no Programa de Pós-Graduação em Ciência Jurídica da UNIVALI. E-mail: jsoares@univali.br.
} 
as argumentações para convencer o sistema jurídico a ser transformado. E isto é feito através da produção do direito, incluindo aqui criação e transformação das normas e instituições vigentes. De certo modo, é papel da Política Jurídica verificar as necessidades sociais e organizá-las dentro da lógica da tradição jurídica vigente, como alertara Ross. O político do direito, então, é um intelectual que deve efetuar o papel de identificar as necessidades históricas, mas para isto precisa de formação filosófica, capacidade crítica de mediar as necessidades tendo em vista um quadro geral da existência humana. Isto porque verificar as necessidades não se reduz a averiguar o que a sociedade anseia, mas também aquilo que ela, de fato, precisa, enquanto condição biológica e espiritual.

Ou seja, a Política Jurídica não é uma atividade nem meramente empírica nem apenas teórica. $\mathrm{O}$ direito é uma manifestação cultural humana que normativiza a conduta dos indivíduos em dada sociedade. Desse modo, o direito não apenas expressa cultura, mas cria e regulamenta cultura, determina comportamento individual e coletivo. $\mathrm{O}$ direito faz opções do que e como regulamentar, e nestas opções a existência humana pode ser mais funcional ou menos para si.

Neste artigo apresenta-se, a partir do posicionamento de Vaz, a Filosofia como instrumento racional de exame crítico da Cultura, e sendo o direito um fenômeno cultural, objetiva-se defender que deveria a Política Jurídica aprofundar-se no estudo filosófico para ter melhor compreensão da dinâmica humana individual e social. A cultura (incluindo aqui o direito) identifica ontologicamente o ser humano, pois somente ele é capaz de produzir cultura entre os seres vivos deste planeta.

De modo prático a Política Jurídica consiste no exame racional do direito vigente, verificando como transformá-lo, e isto se faz com a consciência crítica capaz de analisar o fenômeno cultural. A filosofia é sempre produto histórico de uma dada sociedade, mas depois que surge, tem a possibilidade de examinar a própria cultura que lhe originou, como é o caso, por exemplo, de Sócrates analisando a filosofia de seu tempo, inclusive criticando os dogmas religiosos da época. Sendo assim, pode a filosofia ser referencial teórico para a Política Jurídica, ensinando-a a examinar criticamente a cultura jurídica vigente, à luz tanto dos anseios históricos como do horizonte do ser. Para além da diversidade cultural existe a unidade que subjaz ao fenômeno cultural em si, e para além da diversidade humana existe uma unidade que identifica ontologicamente o ser humano. A Filosofia age neste ponto, ensinando a Política Jurídica a examinar criticamente a cultura à luz da ontologia humana. 
Portanto, o problema de pesquisa é: pode a Filosofia ser instrumento de auxílio da Política Jurídica no exame crítico do direito vigente enquanto manifestação cultural?

$\mathrm{O}$ artigo utiliza o método dedutivo, por meio de pesquisa bibliográfica.

\section{FILOSOFIA E POLÍTICA JURÍDICA}

A filosofia, desde suas origens pré-socráticas, se revela um instrumento capaz de colocar qualquer objeto sob análise crítica. A filosofia, na medida em que exercita o conhecimento de como se pensar, permite justificar ou criticar qualquer objeto, colocar em exame qualquer pensamento. ${ }^{2}$

Do ponto de vista histórico a filosofia pode ser entendida como produto da cultura grega. A filosofia nasce na Grécia, como resultado de séculos de desenvolvimento intelectual com as poesias épicas, com as tragédias e comédias $^{3}$, com toda uma tradição que busca desvelar o real, até o surgimento de Tales de Mileto e dos demais pensadores ditos présocráticos, pesquisadores da cosmologia. A filosofia, nesse sentido, é produto da cultura, da cultura grega.

Mas a filosofia, no momento em que nasce, consegue se libertar da cultura que a gerou, se torna um instrumento livre capaz de examinar e criticar até mesmo a. cultura que lhe deu causa. Sendo assim, já em seu período incipiente se vê Xenofonte dizendo que se os animais cultuassem deuses o fariam criando as divindades com patas e chifres, às suas imagens. Depois Sócrates seria condenado também por criticar os deuses da tradição de seu povo. Ou seja, a cultura que gera a Filosofia não está livre de ser examinada e criticada pela Filosofia.

Desse modo se vê como a relação entre Cultura e Filosofia é intrincada. De um lado toda corrente filosófica, todo pensamento filosófico, é fruto de uma época, de uma cultura, de uma dada sociedade histórica. Assim, a filosofia grega nasce da cultura grega, a medieval da sociedade medieval, as correntes modernas dos modos econômicos e sociais de organização dos Estados modernos. Mas mesmo isto não impediu filósofos gregos de criticarem a cultura grega, de filósofos medievais colocarem em exame a tradição medieval, e assim por diante.

\footnotetext{
${ }^{2}$ Para uma exposição desta capacidade da filosofia examinar criticamente os elementos culturais dados na história humana ver Soares (2019).

${ }^{3}$ Ver Jaeger (2005).
} 
Portanto, a Filosofia tem a capacidade de mediar o exame crítico de qualquer realidade cultural, incluindo aquela que lhe gera. Com o surgimento da racionalidade científica moderna a Filosofia potencializa esta capacidade, pois passa a dispor de outros instrumentos técnicos (provenientes da metodologia científica) para analisar e criticar a realidade cultural.

Avançando na abordagem o filósofo e o cientista se deparam com a constatação de que a cultura é plural, de que existe uma imensa pluralidade e diversidade de culturas ao redor do planeta e no tempo. Do ponto de vista é empírico é inviável falar em modelo de cultura ideal, diante da evidência da profunda diversidade que toca a realidade humana.

Trata-se, na verdade, de uma pluralidade não só quantitativa no espaço e no tempo históricos, mas qualitativamente interior a cada paradigma cultural, que apresenta sempre uma estrutura em processo incessante de autodiferenciação. A cultura mostra aqui sua solidariedade profunda com a vida que também se autodiferencia numa profusão quase infinita de formas e que mostra de maneira poderosamente original esse dinamismo autodiferenciador justamente na vida da cultura. (VAZ, 2002a, p. 89).

Toda cultura é um fenômeno da vida, no sentido de que se manifesta a partir da interação histórica de um dado grupo com as circunstâncias existenciais que o tocam. Sendo assim, diversa é a aparência cultural, porque diversas são as circunstâncias que influenciam o agir humano.

No entanto, se por um lado a evidência empírica atesta a multiplicidade cultural, por outro há algo de unitário que subjaz às diferenças culturais, a unidade que persiste apesar das diversidades empíricas. Desse modo a filosofia retoma a discussão que a instiga desde suas origens, a relação entre o uno e o multíplice. Como identificar o uno que está para além do multíplice fenomênico?

Este estudo é possível porque, de qualquer forma, o fundamento da cultura se encontra sempre em seu criador: "a ontologia da cultura é um desdobramento da ontologia do homem, a antropologia filosófica". (VAZ, 2002a, p. 89). Para Vaz o ser humano se constitui ontologicamente na capacidade de criação cultural, vez que isto o distingue dos demais seres vivos.

Assim, ao se criar uma cultura específica, localizada espacialmente e temporalmente, o ser humano permite que aquela obra obtenha transcendência dos limites espaciais e temporais, pois o resultado passará a integrar a ontologia da cultura, o mundo da cultura. Desse modo, a 
criação cultural grega, com sua filosofia e sua poesia, por exemplo, persiste como criação cultural, ainda que o povo que a tenha gerado já não exista historicamente. ${ }^{4}$

Vaz prossegue no raciocínio:

Qual a natureza da unidade da cultura pensada numa conceptualidade filosófica e que afirmamos subjacente à multiplicidade empírica das culturas? Trata-se de uma unidade analógica justamente porque o ato criador do objeto cultural é expressão da abertura do homem à universalidade do ser e é no horizonte dessa universalidade que a obra de cultura se situa e adquire a sua idealidade simbólica. Devemos dizer, pois, que a unidade da cultura é conceptualmente assegurada pelas categorias de estrutura e relação estabelecidas pela antropologia filosófica e articuladas discursivamente pelo movimento dialético de autoexpressão do sujeito, impelido do princípio da 'ilimitação tética'. A unidade é, pois, uma unidade na diferença (por isso mesmo unidade analógica) que permite ao homem realizar-se na pluralidade das culturas históricas e na rica profusão de formas por elas ostentadas. (VAZ, 2002, p. 90-91).

A cultura, assim, reside na dialética de transcendência do humano como abertura ao horizonte do ser. Na produção cultural o ser humano afirma sua condição ontológica de alguém que cria a própria morada espiritual em meio às circunstâncias concretas (ambientais, tecnológicas, econômicas, etc.) que lhe tocam. ${ }^{5}$

Assim, o ser humano é ser cultural, que se desdobra em ser jurídico, ser religioso, ser econômico, ser político, ou seja, em manifestações espirituais do indivíduo na relação com os demais e com a transcendência do ser. E o universo cultural do humano é um universo simbólico, suscetível a exame crítico racional de seus fundamentos e consequências, por meio da atividade filosófica.

Entretanto, na medida em que o ser humano cria a cultura ele depois também tende a ser normatizado por ela, regulamentado por ela. A cultura, desse modo, apresenta paradoxo, é criada e cria o indivíduo, porque mediada por ele, depois medeia regras e expectativas de comportamento que formatam a pessoa em determinado estilo de vida. A cultura, produzida

\footnotetext{
4 "O ato da criação cultural deposita a obra da cultura no aqui e agora da existência histórica do homem e no tempo do mundo, e ela passa a existir - com uma existência precária e ameaçada - arrastada no fluxo das coisas temporais. No entanto, pela forma a obra penetra no universo simbólico, que lhe assegura uma perenidade ideal". (VAZ, 2002a, p. 90). O fato de a criação cultural específica ter existência precária e ameaçada deve-se, provavelmente, e, à razão de a criação cultural depender da memória e da preservação dos registros históricos. ${ }^{5}$ A dimensão ontológica do ser humano já foi abordada por inúmeros filósofos ao longo da história, desde a concepção de alma baseada na teoria do mundo das formas em Platão até as mais recentes pesquisas fenomenológicas, passando por toda a contribuição medieval e moderna. Para aprofundamentos ver Mondin (1998). Entre autores contemporâneos cita-se Meneghetti (2010), que especifica a dimensão ontológica humana a partir do conceito de Em Si ôntico, enquanto princípio formal inteligente capaz de fazer autóctise histórica, intuindo nas circunstâncias históricas a solução ideal para cada contexto.
} 
pelo homem, influencia a criação jurídica, impacta na forma de o próprio homem se comportar. A ontologia da cultura tem sua continuidade na ética da cultura.

\title{
2 ÉTICA E CULTURA
}

A cultura, como obra humana, é mediada pela práxis, pela ação histórica individual e coletiva. Neste aspecto, a cultura inevitavelmente se coliga à ética enquanto ciência do ethos, ciência do comportamento humano que tende à normatividade. Os costumes, as normas, as instituições, não são dados naturais, mas criações humanas na dialética histórica com o mundo dado. O direito, neste sentido, está situado no mundo simbólico da cultura, da criação do ethos como morada espiritual do homem.

\begin{abstract}
A normatividade da cultura é tão evidente quanto a sua própria existência, pois é claro que o mundo cria o mundo da cultura tendo em vista o seu próprio bem. O ético não deve, pois, ser entendido como um predicado que advenha ab extrinseco à cultura. Os dois conceitos são coextensivos, pois todas as obras da cultura encontram seu lugar no espaço do ethos, que é, propriamente, a morada do homem sobre a terra. Nesse sentido, o ethos pode ser dito 'a forma de vida' (lebensform) da cultura. Ora, a Ética não é mais do que a "ciência do ethos" e é, portanto, pela sua própria natureza, a ciência normativa da cultura. Fazendo-se reflexão ética, a reflexão filosófica sobre a cultura tem em vista, pois, o dever-ser presente constitutivamente no operar do homem e nas suas obras. (VAZ, 2002a, p. 93).
\end{abstract}

O ethos é a morada do homem porque a partir da normatividade da cultura o ser humano é capaz de mediar sua relação com o mundo. Ao viver simbolicamente no reino da cultura o ser humano cria uma segunda natureza, para além daquela primeira constituída pelo diretamente pelo ser que o transcende. A funcionalidade desta segunda natureza, no entanto, depende de sua conexão com a primeira. Talvez por isto o ethos humano esteja em contínua mutação, vez que está sempre se adaptando às exigências históricas para tentar melhor harmonizar a segunda com a primeira natureza.

É a partir de comportamentos organizados e mediados diante da Natureza que o mundo se torna morada do homem e não um Outro exterior, e é a partir da inserção em uma Sociedade que o homem se eleva além da pura individualidade e passa a integrar âmbitos como o cultural, o científico, o religioso, o jurídico. Através da comunidade ética na integração com a Natureza e o Outro (Sociedade) o homem se vincula não somente aos demais indivíduos contemporâneos, mas àqueles que vieram antes, da qual é herdeiro de um 
ethos, e daqueles que virão, que herdarão o ethos gerado continuamente. O ethos é a expectativa comportamental dentro de dada comunidade ética, uma reciprocidade de valores, de condutas, de direitos e deveres, que estabiliza as relações sociais e permite aos sujeitos dirigirem suas inteligências a atividades maiores, como a política, a empresarial, a cultural, a científica, a filosófica, etc. ${ }^{6}$

Vaz lembra que para os gregos a expressão ethos englobava dois sentidos distintos e complementares ao mesmo tempo, porque de um lado o termo significa o comportamento habitual do indivíduo, enquanto práxis diária subjetiva, e por outro o conjunto de comportamentos comunitários aceitos, sendo aqui o estabelecimento dos costumes.

Mas tanto o ethos enquanto hábito individual quanto aquele do costume social derivam da praxis, dos atos concretos humanos no tempo. É hábito somente aquilo que o indivíduo exercita continuamente e é costume somente aquilo que a comunidade exercita continuamente. Portanto, o ethos, tanto individual como social, decorre da praxis, somente apreendida pela observação. (VAZ, 2002b).

E se a Ética é a ciência do ethos, ela não pode ser simplesmente a observação dos hábitos individuais e dos costumes sociais, porque como ciência ela comporta sempre uma reflexão racional, e por ser mais especificamente atividade filosófica, uma reflexão filosófica sobre os ethos. A Ética é o estudo do ethos individual e do ethos social. (VAZ, 1999, p. 65).

Os hábitos individuais e os costumes sociais são definidos pela praxis. Mas a praxis em si mesma é apenas uma repetição no tempo, uma sequência de atos feitos reiteradas vezes. A praxis em si mesma é incapaz de medir a qualidade e a funcionalidade dos comportamentos, tanto individuais como coletivos. Daqui surge a necessidade da Ética, da reflexão filosófica sobre a praxis dos comportamentos, verificando o sentido e funcionalidade dos mesmos, para os indivíduos e para as comunidades. (VAZ, 1999, p. 85).

Por sua vez o ethos social deságua nos costumes, no conjunto de praxis coletivas que configurariam o comportamento padrão em determinado grupo (família, polis, etc.). É a partir dos costumes que se formalizam os nomos, isto é, as leis e regras jurídicas, escritas ou não escritas, que organizariam a vida comunitária.

No ethos o indivíduo não age somente diante da natureza, mas dentro de um universo simbólico estabelecido no qual se encontra seguro, porque a partir daquele ato espera

\footnotetext{
${ }^{6}$ A exposição do direito como manifestação racional que participa da construção de uma segunda natureza humana pode ser estudada a partir de Soares (2018).
} 
determinadas respostas dos outros. Ao propor a compra de determinado produto pode esperar a negociação, ao se dedicar a fazer poesia pode esperar a apreciação estética alheia, quando se dedica a empreender negócios sabe que o seu resultado será avaliado pelos demais, ou seja, ele age dentro de um conjunto de comportamentos previamente conhecidos, de tal modo que pode prever resultados e respostas dos demais. Neste aspecto o ethos é sempre uma morada, porque protege, dá abrigo, e ao mesmo tempo estabelece limites, coloca início e fim da liberdade dos comportamentos. O sujeito, em uma comunidade ética, pode invariavelmente identificar onde começa e onde termina o seu direito. ${ }^{7}$ A literatura, a ciência, a política, a economia, qualquer campo onde se aplique a inteligência humana, somente é possível se antes existe a morada espiritual do ethos, um conjunto de comportamentos estabelecidos que possibilitam as relações de reconhecimento entre os indivíduos em dada comunidade.

A comunidade ética é possível na medida em que existe harmonia do ethos individual com o ethos social, isto é, daquilo que os indivíduos buscam para suas existências privadas e daquilo que a comunidade consagra como costumes. A funcionalidade das leis e das instituições jurídicas depende de uma relação de reconhecimento intersubjetivo entre os membros da comunidade ética. Por ser dessa forma é que o ethos tende sempre a ser tradicional, no sentido de que se histociza, se torna permanente no tempo no seio de cada comunidade. Sem esta tradicionalidade não há como os costumes se firmarem enquanto medidas objetivas para o comportamento social. ${ }^{8}$

Em síntese, a Ética como ciência do ethos individual produz o estudo filosófico do comportamento individual visando a excelência, satisfação máxima da vida conforme a identidade ontológica de cada, e a Ética como ciência do ethos social produz o estudo filosófico do comportamento comunitário gerador de costumes, que por sua vez dá origem ao

\footnotetext{
${ }^{7}$ Interessante notar a metáfora do ethos enquanto morada espiritual na comparação com a ecologia enquanto morada física do homem, realizada por Vaz: "Do ponto de vista da sua plena autorrealização o ser humano, antes de habitar o oikos da natureza, deve morar no seu oikos espiritual - no mundo da cultura - que é constitutivamente ético. A simples preservação do ecossistema natural perderia toda significação humana se não se operasse a partir de uma concepção ética da vida e não fosse entendida como pressuposto necessário, mas não suficiente para a satisfação das necessidades não apenas físicas, mas sobretudo espirituais do homem". (VAZ, 1999, p. 40. Este trecho produz instigante reflexão filosófica sobre a sustentabilidade, pois esta deve ser vista não como proteção do ecossistema em si, mas como condição para o homem poder satisfazer necessidades ainda mais elevadas, que preencham suas expectativas espirituais.

${ }^{8}$ É importante destacar que o costume enquanto medida do ethos social é um dado geral, existente em qualquer comunidade ética, independente de seu ordenamento jurídico seguir aquilo que comumente se chama common law ou civil law, isto é, o direito baseado nos costumes ou na autoridade da lei emanada pelo Estado. Isto porque mesmo os países que consagram o legislativo enquanto criador do direito este, em sua atividade político-jurídica, acaba por prestar contas com a opinião pública social, na medida em que as leis criadas são avaliadas se correspondem ou não aos costumes estabelecidos naquele contexto histórico
} 
nomos, às leis e regras jurídicas. (VAZ, 1999, p. 60)

\begin{abstract}
A Ética da cultura começa por investigar o caráter deôntico ou normativo com que o ser se apresenta ao homem na atividade de livre criação com que este constrói nele a sua morada, ou seja, exatamente, na cultura. Essa normatividade do ser não é mais do que a exigência do bem ou do melhor (agathon) conferindo à atividade humana sua estrutura teleológica e constituindo o homem como um ser essencialmente ético. A transcrição histórica da essência ética do homem tem lugar em toda extensão do espaço simbólico que, justamente, denominamos cultura. (VAZ, 2002a, p. 95).
\end{abstract}

Portanto, se a ação humana é orientada no sentido de realizar o que é melhor para si, enquanto indivíduo e coletividade, a normatividade desta operação acabará sendo escrito por meio da cultura e seu universo simbólico. Desse modo há íntima correlação entre o ser cultural e o ser ético ${ }^{9}$ em uma dada especificidade social histórica. (VAZ, 2004).

Mas esta correlação não é absoluta, do contrário a cultura e a ética seriam estáticas. A cultura e a ética se modificam porque se modificam as condições históricas da existência humana. As mudanças, no entanto, não são automáticas, mas mediadas pela racionalidade humana. A tarefa de mediar esta passagem na forma mais funcional ao ser humano pertence à Filosofia. A Filosofia, portanto, pode analisar criticamente a especificidade cultural existente, verificando como aprimorá-la, como mediá-la historicamente ao melhor teleológico do ser humano.9

\title{
3 FILOSOFIA E POLÍTICA JURÍDICA
}

A Política Jurídica, ou Política do Direito, é a disciplina que estuda o Direito que deve ser e como deva ser em contraponto a dogmática jurídica que estuda a interpretação e aplicação do Direito vigente. (MELO, 2000, p. 77).

Essa disciplina visa alcançar o Direito desejado pela Sociedade, pautando-se, assim, nos critérios de Ética, Justiça, Legitimidade e Utilidade. Para alcançar um Direito que atenda a esses critérios, é necessário a propositura de novas normas, adequação daquelas existentes e a reconceituação do próprio Direito e de seus núcleos. (CAVEDON, 2011, p. 65).

Cabe à Política Jurídica a percepção e apreensão dos desejos e necessidades da Sociedade, introduzindo no sistema ${ }^{10}$ jurídico elementos valorativos que foram afastados pela dogmática jurídica em nome da segurança. (MELO, 2000, p. 77).

\footnotetext{
${ }^{9}$ Para aprofundamentos sobre o ser ético, em uma perspectiva ontológica, ver Meneghetti (2018).

${ }^{10}$ Para estudo filosófico da interação entre cultura e sociedade ver Meneghetti (2002).
} 
Para a Dogmática Jurídica é válida toda norma positivada, desde que autorizada por norma superior, elaborada por autoridade competente e com fiel observância aos ritos do processo legislativo. Porém, para a Política Jurídica, a validade de uma norma não pode ser extraída apenas do seu aspecto formal, mas deve considerar também a legitimidade ética de seu conteúdo e de seus fins. (MELO, 1994, p. 87-88).

Sendo assim, a Política do Direito busca, tanto em fontes formais ou informais, as representações jurídicas do imaginário social que tenha legitimidade na ética, nos princípios de liberdade e igualdade e na estética da convivência humana. (MELO, 1994, p. 131).

A Política do Direito deve buscar um Direito que por meio de suas normas crie um ambiente em que se permite a estética do conviver, que permite aos homens um mínimo de auto-respeito e reconhecimento recíproco da dignidade ${ }^{11}$ de cada um, tanto no relacionamento entre si quanto no relacionamento com o ambiente, com o mundo. (MELO, 1994, p. 63).

A Estética aparece como forma de se buscar o mais belo do homem, da norma, do Direito. O Esteticismo é uma expressão usada para significar uma atitude que dê importância superior aos valores estéticos nos fatos da vida. $\mathrm{O}$ homem ético é aquele inconformado com o injusto e com o incorreto, o homem estético é não pode conformar-se com o feio produzido pelo injusto e pelo incorreto. (MELO, 1994, p. 62). Pergunta Osvaldo Ferreira de Melo (1994, p. 62):

Se a grande função da arte é propiciar prazer espiritual, que prazer maior para o ser humano sensível do que o bem-conviver, a comunicação aberta, o sentir-se aceito na diversidade, e descobrir-se com as condições psicológicas e culturais de aceitar o pensar do outro?

A arte de viver é uma constante colocação da estética na convivência, é criar um ambiente favorável para o desenvolvimento da tolerância, do pluralismo de ideias, da aceitação dos valores dos outros. A democracia, na sua mais elevada acepção, quando transcende simples arranjos políticos, tem sua estética própria. (MELO, 1994, p. 62).

Para a Política Jurídica, é necessário rever as fontes tradicionais do Direito, para privilegiar aquelas que realmente sustentem um Direito novo, desejável, criativo, libertador, racional e que cumpra sua função de responder aos anseios sociais. (MELO, 1994, p. 131).

Os objetivos da ação político-jurídica visam à desconstrução de paradigmas que negam ou impedem a criatividade como um agir permanente, assegurando, assim, a

\footnotetext{
${ }^{11}$ Para estudo da dignidade da pessoa humana enquanto construção possível do indivíduo ver Soares e Locchi (2016).
} 
valorização do ser humano e a dignidade de tratamento dos homens entre si e com a natureza. (MELO, 1994, p. 132).

Na obra Temas Atuais de Política do Direito,Melo destaca alguns pontos acerca da importância do estudo da Política Jurídica, primeiramente destacando a própria relação entre Política e Direito, afirmando que é possível e desejável uma teorização sobre a conciliação entre Política e Direito, entendidas ambas as categorias em um sentido ético-social e identificados os respectivos conceitos, tanto quanto possível, com a ideia do justo e do legitimamente necessário, ou seja, do socialmente útil. (MELO, 1998, p. 14).

Em decorrência dessa reciprocidade, o Direito necessita da Política para continuamente renovar-se nas fontes da legitimação, e a Política necessita do Direito para objetivar as reivindicações sociais legítimas, ou seja, propor um sistema de categorias, conceitos, princípios e normas capazes de assegurar não só relações econômicas mais justas, mas também o alcance de um ambiente social realmente ético e estimulador das práticas solidárias. (MELO, 1998, p. 14).

As teorias para fundamentar as técnicas de construção, interpretação e aplicação da norma preocupam-se prioritariamente com a lógica ou outras formalidades, descompromissadas com o conteúdo ético que é próprio da natureza do Direito, sendo usadas indiscriminadamente para desmandos autoritários e atendimento a reivindicações sociais. Já a Política do Direito, arquitetada sobre critérios de prudência e possibilidades e fundamentada em padrões éticos, estará a serviço de um devir desejável e realizável, como proposta criativa aos desafios que forem surgindo. (MELO, 1998, p. 14).

A Política Jurídica não é descritiva, é prescritiva, comprometida com as necessidades e interesses sociais, e sempre interessada nos conhecimentos que lhe podem oferecer a Ciência Jurídica, a Filosofia do Direito e a Sociologia Jurídica, na busca dos aportes teóricos necessários à compreensão dos fenômenos jurídico e social. (MELO, 1998, p. 14).

Importante o destaque de que a Política Jurídica não é pura teoria, mas é voltada para o agir. Toda ação corretiva e criativa recairá sobre o sistema normativo vigente, influindo na sua permanente adequação e aperfeiçoamento. (MELO, 1998, p. 14).

No entanto, este agir não pode ser sinalizado somente a partir de indicações empíricas, verificando estatisticamente os anseios sociais, mas ponderado a partir do horizonte do Ser, da dimensão ontológica do ser humano, porque dali se extrai os valores como fundamentos do direito. Observa-se o que diz Motta (2008, p. 351): 
O Ser, como ente supremo do universo, constituído de índole política, busca, pelo conhecimento, criar leis morais para a convivência em Sociedade. A consciência da necessidade de regras morais, no sentido do bem coletivo, torna-o Ser do Dever-Ser. A intencionalidade do Ser, do Dever-Ser, forma a cultura. Ou seja, tudo o que Ser acresce à natureza do mundo, por sua vontade racional, no sentido de inovar, de modificar, de criar algo, constitui a cultura.

Portanto, o mundo jurídico é produto da intencionalidade advinda do horizonte do Ser, sendo assim, não podem especificidades jurídicas serem examinadas somente à luz da empiria, mas também mediante o emprego de uma racionalidade filosófica capaz de examinar os elementos existenciais a partir de uma ótica universal, que possa avaliar qualquer elemento cultural determinado historicamente. Aqui retoma-se o argumento trabalhado na parte anterior do artigo, da cultura como uma segunda natureza acrescida à primeira natureza, constituída no mundo físico. Esta segunda natureza, cultural, participa da morada espiritual do homem, o mundo do ethos, porque é no estabelecimento espiritual de comportamentos que o ser humano começa a determinar a própria conduta também a partir da livre vontade racional, não apenas como consequência do mundo dado.

Reale emprega feliz ideia para definir a cultura. O ser humano, utilizando-se das leis naturais, construiu para si um segundo mundo sobre o mundo dado, consistente no mundo da cultura, mundo histórico. Valor, como fenômeno cultural, apresenta estreita relação com a história. (MOTTA, 2008, p. 351).

A abordagem de Motta segue o raciocínio de Reale, mas possui conexão com aquilo que foi apresentado por Vaz.

Para Vaz a cultura, apesar de diversa em sua constatação empírica, possui uma unidade ontológica que persiste, sendo esta unidade derivada da cultura como sendo produto humano, integrante da natureza ontológica humana. O ser humano se afirma assim por ser capaz de construir a própria morada espiritual no ethos, e o faz mediante ação cultural.

A Política Jurídica, seguindo este raciocínio, lida com a diversidade de manifestações do mundo jurídico, porque sendo o direito elemento que integra a cultura será também, inevitavelmente, diverso, vez que assim se dá a existência social humana.

Mas a diversidade inclui a transição, a mudança, de modo que as regras e instituições jurídicas não são estáticas, mas se transformam continuamente a partir dos influxos culturais e necessidades históricas. $\mathrm{O}$ jurista, enquanto cientista e operador prático, tende a ter facilidade para instrumentalizar o direito positivo dado, já estabelecido dentro de uma sistemática ou 
ordenamento. Mas este conhecimento é insuficiente para se verificar o que deve ser modificado e aprimorado no direito vigente.

Nesta área de pesquisa adentra-se a Política Jurídica, na investigação do que deve ser mudado e aprimorado nas regras vigentes. A Política Jurídica, assim, analisa a cultura jurídica e propõe soluções para os problemas correntes. Mas como o faz? Não pode fazê-lo somente com raciocínios estatísticos e empíricos, mas também analisando a cultura jurídica a partir de referenciais ontológicos, que sejam capazes de verificar aspectos da existência humana individual e social na interação com o horizonte do ser. Isto é possível recorrendo-se ao estudo filosófico e, mais apropriadamente, ontológico, pois este consiste justamente em submeter o multíplice a exame, verificando o que há de unitário que persiste apesar das diversidades empíricas. A filosofia, assim, pode ser fundamental instrumento racional de auxílio à Política Jurídica no exame crítico dos valores culturais e manifestações da cultura jurídica especificamente dada, verificando como aprimorá-las no objetivo de propor melhores alternativas que facilitem uma vida humana mais digna e satisfatória, seja enquanto indivíduo, seja enquanto sociedade ou humanidade.

\section{CONSIDERAÇÕES FINAIS}

Na primeira parte deste artigo apresentou-se a conexão entre as ideias de Filosofia e Cultura, na perspectiva de que a Filosofia é sempre um fenômeno cultural, originado dos valores e instituições específicos de uma dada sociedade, historicamente e espacialmente localizada. Mesmo em sua origem é difícil separar a Filosofia das condições históricas que lhe propiciaram nascer, isto é, a cultura grega antiga.

No entanto, no momento em que nasce, a Filosofia, como exercício da racionalidade que desvela o real, se torna capaz de examinar criticamente inclusive a cultura que lhe origina A cultura cria a filosofia, mas mesmo ela não está livre de seu escrutínio. Assim ocorre com Sócrates, que critica os fundamentos religiosos da sociedade em que vive, e em tantos outros momentos históricos posteriores.

A Filosofia possui esta faculdade, lembra Vaz, porque a Cultura, apesar de sua diversidade empírica, possui uma unidade de base que a subjaz ontologicamente. Cada criação cultural, apesar de historicamente definida, se torna obra, e nisto passa a integrar um patrimônio cultural trans-histórico, ainda que precariamente existente, porque depende da memória humana. Os elementos culturais podem, nesse caso, serem examinados à luz da 
racionalidade filosófica, que o faz também porque a cultura integra a ontologia humana, no sentido de que somente o ser humano, entre os seres vivos, é capaz de criar um mundo simbólico e nele viver, o mundo da cultura. O ser humano não apenas vive no mundo natural, mas o transforma, o ressignifica, e o instrumento utilizado para isto é a cultura.

O direito integra o mundo da cultura, é um dos instrumentos que a cultura utiliza para criar a morada espiritual humana. A cultura, assim, não apenas cria condições espirituais para convivência humana, mas também estabelece normatividade, regulamentação dos comportamentos humanos em dada sociedade.

Por fim, as regras jurídicas não podem ser estáticas, porque as necessidades sociais mudam, e aqui faz-se a passagem para a segunda parte do artigo, dedicada à Política Jurídica.

Se a Política Jurídica é a disciplina que busca responder como o direito deveria ser, para isto ela precisa ter a competência de não apenas identificar os anseios históricos de uma certa sociedade, mas analisá-los à luz da dialética entre ser humano e horizonte do ser, isto é, de como estas alterações jurídicas podem melhorar a mediação humana tendo em vista o sumo bem.

Nesse aspecto a Política Jurídica não pode ser apenas um estudo empírico, mas ter a possibilidade de examinar elementos culturais a partir de uma perspectiva racional ontológica.

É certo, deste modo, que a Política Jurídica precisa do auxílio da Filosofia, porque esta possui justamente a competência de examinar qualquer aspecto cultural, porque pondera aquilo que é específico à luz da universalidade.

Desse modo, conclui-se reafirmando a necessidade da Política Jurídica aprimorar e aprofundar sua dimensão filosófica, ou ainda mais, ontológica, do contrário corre o risco de se tornar apenas pesquisa empírica, e com dificuldade de avaliar quando as mudanças propostas serão capazes de criar melhores condições de vida para o indivíduo e sociedade. O retorno à dimensão ontológica permitiria à Política Jurídica retomar sua condição de vela que ilumina o caminho dos juristas e políticos, apresentando a direção a ser tomada tendo em vista a construção de uma sociedade mais funcional ao ser humano enquanto indivíduo e sociedade.

\section{REFERÊNCIAS BIBLIOGRÁFICAS}


CAVEDON, Fernanda de Salles; VIEIRA, Ricardo Stanziola. A Política Jurídica e o Direito Socioambiental:uma contribuição para a decidibilidade dos conflitos jurídicos-ambientais. Novos Estudos Jurídicos, Itajaí, edição especial, p. 60-78, 2011.

JAEGER, Werner. Paideia: a formação do homem grego. São Paulo: Martins Fontes, 2005.

MELO, Osvaldo Ferreira de. Dicionário de Política Jurídica. Florianópolis: OAB-SC, 2000.

MELO, Osvaldo Ferreira de. Fundamentos da Política Jurídica.Porto Alegre: Sergio Antonio Fabris; CPGD-UFSC, 1994.

MELO, Osvaldo Ferreira de. Temas Atuais de Política do Direito. Porto Alegre: Sergio Antonio Fabris, 1998.

MENEGHETTI, Antonio. O critério ético do humano. Recanto Maestro: Ontopsicologica Ed., 2018.

MENEGHETTI, Antonio. Manual de Ontopsicologia. Recanto Maestro: Ontopsicologica Ed, 2010.

MENEGHETTI, Antonio. Sistema e Personalità. Roma: Psicologica Ed., 2002.

MONDIN, Battista. Storia della Metafisica. Bologna: Studio Domenicano, 1998.

MOTTA, Moacyr Motta da. A ideia de Valor como fundamento do direito. In: CADEMARTORI, Daniela Mesquita Leutchuk de; GARCIA, Marcos Leite. Reflexões sobre Política e Direito: Homenagem aos Professores Osvaldo Ferreira de Melo e Cesar Luiz Pasold. Florianópolis: Conceito, 2008.

SOARES, Josemar. Consciência de Si, Direito e Sociedade. São Paulo: Intelecto, 2018.

SOARES, Josemar. Filosofia do Direito. Curitiba: IESDE, 2019.

SOARES, Josemar; LOCCHI, Maria Chiara. O papel do indivíduo na construção da dignidade da pessoa humana. Revista Brasileira de Direito, v. 12, n. 1, 2016.

VAZ, Henrique de Lima. Ética e Cultura: Escritos de Filosofia II. São Paulo: Loyola, 2004.

VAZ, Henrique de Lima. Filosofia e Cultura: Escritos de Filosofia III. São Paulo: Loyola, 2002.

VAZ, Henrique Cláudio de Lima. Escritos de Filosofia IV: Introdução à Ética Filosófica 1. São Paulo: Loyola, 1999.

VAZ, Henrique Cláudio de Lima. Ética e Direito. São Paulo: Loyola, 2002. 